\title{
Elihu H. Estey, MD: leukemia expert, statistician, and gentle soul (July 15, 1946-October 8, 2021)
}

Roland B. Walter (iD ${ }^{1,2,3,4}$, Andreas Hochhaus ${ }^{5}$ and Robert Peter Gale (iD ${ }^{6}$

(c) The Author(s), under exclusive licence to Springer Nature Limited 2021

Leukemia (2021) 35:3619-3621; https://doi.org/10.1038/s41375-021-01467-z

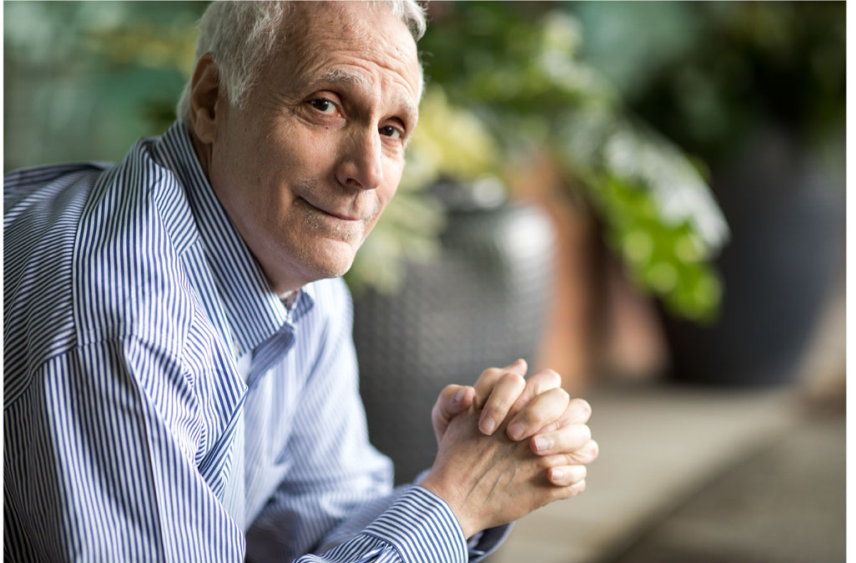

Life is short. Don't do the same thing everyone else is doingthat's such a herd mentality. And don't do something that's two percent better than the other person. Do something that changes the world.

Oren Etzioni.

Prof. Elihu (Eli) H. Estey, a pioneering AML researcher, physician, and scholar collapsed and died unexpectedly on October 8, 2021, at his home in Seattle, age 75 years.

Eli grew up in Brooklyn, New York attending Poly Prep Country Day School, where he believed a major part of the development of his critical thinking took place. He graduated from Yale University with a major in mathematics in 1968 and received his MD degree from Johns Hopkins University in 1972 . His post-MD training was in medicine and neurology at New York University-Bellevue Medical Center. In 1978 he moved to Houston to begin a fellowship in oncology at MD Anderson Cancer Center intending to specialize in neuro-oncology. There he met his lifelong mentor and colleague Prof. Emil J. Freireich [1]. Under Freireich's influence Eli redirected his career to leukemias as a fellow and assistant professor in the Department of Developmental Therapeutics. Many people were surprised by the collegial and personal relationship between Profs. Freireich and Estey. In many ways they seemed opposites, Spinoza and Maimonides (Teach thy tongue to say I do not know' and thou shalt progress). However, they saw the genius in each other for which we are fortunate. From 1983 to 1984, Prof. Estey worked as a Cancer Expert at the Investigational Drug Branch of the Division of Cancer Treatment, National Cancer Institute. He returned to MD Anderson as an associate professor and became a professor in the Department of Leukemia in 1993 and Chief of the Section of Acute Leukemia and Myelodysplastic Syndromes in 1997.

In 2008, he and his family moved to Seattle where he became a professor at the University of Washington and Fred Hutchinson Cancer Research Center. There he built one of the largest clinical AML programmes in the US that quickly gained national and international prominence. RBW was privileged to learn from and work with Eli as his mentor and close friend over these last 13 years.

Improving the lives of people with leukemia was his lifelong passion. His tools were astute observation, hypothesis testing, and especially rigorous data analyses. An out-of-the box (heretical?) thinker, he would routinely question or challenge the validity of widely accepted medical practices. A randomized trial comparing a cooked (neutropenic) versus a normal diet in people receiving intensive remission induction chemotherapy for AML is an example [2]. A neutropenic diet had no advantage over normal food serving only to make peoples' lives worse during difficult times. He critically interrogated data behind many other standard-of-care practices relying on his expertise in mathematics and statistics. Prof. Estey was a great fan of Bayesian statistics (no frequentist he!) and worked extensively with his good friend Prof. Peter F. Thall to develop adaptive clinical trials designs which could give reliable answers absent randomized controlled trials [3].

Several of his studies were practice changing. For example, he introduced the concept of bypassing chemotherapy and treating acute promyelocytic leukemia only with all-trans retinoic acid and arsenic trioxide, now the standard-of-care. Eli authored nearly 700 peer-reviewed articles including several with us. In a

${ }^{1}$ Clinical Research Division, Fred Hutchinson Cancer Research Center, Seattle, WA, USA. ${ }^{2}$ Department of Medicine, Division of Hematology, University of Washington, Seattle, WA, USA. ${ }^{3}$ Department of Laboratory Medicine \& Pathology, University of Washington, Seattle, WA, USA. ${ }^{4}$ Department of Epidemiology, University of Washington, Seattle, WA, USA. ${ }^{5}$ Klinik für Innere Medizin II, Universitätsklinikum Jena, Friedrich-Schiller-Universität Jena, Jena, Germany. ${ }^{6}$ Centre for Haematology Research, Department of Immunology and Inflammation, Imperial College London, London, UK. ${ }^{\circledR}$ email: rwalter@fredhutch.org

Received: 15 October 2021 Revised: 21 October 2021 Accepted: 22 October 2021

Published online: 16 November 2021 
series of articles in LEUKEMIA where he served many years as an Associate Editor, he was brutally honest about what we know and more about what we don't know about treating AML and his objection to several recent US FDA drug approvals [4-8]. Although it's unusual to have references in an obituary several of these are must reads for critical thinkers.

Other contributions were the recommendation not to monitor persons with $A M L$ in remission with serial bone marrows thereby saving them unnecessary distress [9], the cut-point of 20 percent blasts to define AML [10], a threshold he later challenged [11], and doubt about the validity of complete remission with incomplete hematologic recovery as an outcome endpoint in AML with equal weight to complete remission [12]. He was a member of several expert panels such as the European LeukemiaNet where he helped formulate expert consensus opinions and clinical practice guidelines and advised the FDA on the merit of new drugs. Eli was unsurprisingly critical of such processes often quoting Abba Eban: Consensus means that lots of people say collectively what nobody believes individually.

Scientific sessions on AML were often memorable because of Eli. Presenters lived in fear when he raised his hand and sauntered to the microphone. He would often ask one or more pointed questions others didn't think of asking or were afraid (or too polite) to ask. Following highly complex, overly technical presentations he would phrase his question from the position of a simple country doctor. A humble man, the motif was not personal attention or sarcasm but to satisfy his curiosity about what others thought (or, rather, didn't think) of their data. Many presenters struggled to answer.

His inquisitive nature and medical belief could often be distilled into simple sentences such as no drug too stupid to test. This was not disrespect for science-he had great respect for scientists and rigorously conducted experiments but rather the acknowledgment many effective drugs were discovered empirically whereas many drugs brought to clinical testing based on strong preclinical rationale and data ultimately failed. He felt strongly drug testing is inherently comparative and needs controls, even in phase-2. To his dismay, this requirement is often overlooked, a likely explanation why many drugs with most "promising" results from uncontrolled phase- 2 studies ultimately fail. He proved this in a devastating analysis of the final outcomes of American Society of Hematology annual meeting presentations reporting encouraging results, proof-of-principle or warrant further study and other euphemisms [13].

Challenging trainees and colleagues to think critically was close to Eli's heart. House-staff and fellows were asked: what was the patient's peanut butter hydrogenase when laboratory results were read to him from the medical record without context of the patient's illness or its significance weighed. To remind people of the extraordinary costs of health care from unnecessary testing he would give dollar bills to perpetrators. But he was thrilled when someone with an interest in AML approached him. He was an avid and dedicated teacher, a medical Socrates. A mini-Luddite, he kept a several pages-long list of clinically relevant yet often overlooked questions and reviewed it with each mentee to find a project right for them. He advised them the plural of anecdotes is not data. Eli took pride in his AML database which he diligently curated and used as basis for many of his groundbreaking studies. Whilest striving for and adhering to the strictest scientific standards, his approach to research was practical and grounded in reality directed to moving leukemia therapy forward. His motto: Don't let the perfect be the enemy of the good. Let's take advantage of whatever small progress we make.

Prof. Estey was the best kind of clinical trialist. Yet he stressed the point of a protocol is to treat the person reminding us that research is only a pathway to our primary purpose: caring for people. In a recent obituary for Prof Freireich Eli quoted him saying; The primary beneficiary of clinical research is the patient participating in that research [14]. Eli's version was Don't let the protocol or data interfere with your primary responsibility as a physician. He bonded easily with his patients who adored him, his: prepare for success mindset assured them and he oftentimes took paths which might frighten other physicians. Interestingly, some aspects of Freireich's and Eli's concept of clinical trials participation is at odds with the notion participation in a randomized controlled trial is for the benefit of future people.

Over a long career Prof. Estey mentored many physicians who have become leaders in hematology today globally. His scientific collaborators are myriad and too many to mention. He and Prof. Judith E. Karp were born on the same day (Linda Ronstadt also), called themselves twins and spoke for an hour every Saturday on a wide range of topics including leukemia, politics and sports (Judith was a listener on the latter).

Eli was kind and unobtrusive in his guidance and generous with crediting trainees and junior faculty. He took great pleasure in watching his mentees' projects evolve under his benign supervision. (He could not tolerate fools or phonies.) Many remember early morning walks during meetings to catch up socially and discuss anything from politics to professional sports, of which he was a huge fan and, unsurprisingly, knew all kinds of statistics about. He applied his mathematical background to organizing a betting lottery during the college basketball championship; a beneficent Meyer Lansky. Each week he awaited with equal enthusiasm the New England Journal of Medicine and Sports Illustrated.

Elihu (א ל יהוא), his namesake, is a character from the Book of Job (32:2). Elihu, a descendent of Abraham, makes a brief appearance in which he criticizes Job and his 3 friends claiming God is supreme and that one must acknowledge and submit to that supremacy because of God's wisdom. Why Eli's parents so named him is unclear but for our Elihu God was reason and rationality. It's likely he was the only boy in his class with this name which may have spurred critical thinking and developing boxing skills.

Eli was a gentle soul, a true gentleman not by dress code but demeanor, capable of building bridges between people with different and sometimes difficult personalities. He held some unconventional views and in the ensuing debate he was always thoughtful and respectful playing the topic, never the person. To those who knew him, he was bigger than life, not only in science but in his humanity and sense of humor. He would love to sit down and talk with people (he brought potato chips to share). A rigorous clinical scientist, an impactful thought leader, a wonderful academician, a professional and college sports connoisseur, a fierce advocate for women's rights and equality and a tremendous friend, he will be sorely missed. In Eli's own words: if you have two quarterbacks, you have no quarterback. We just lost ours. A one-of-a-kind mensch.

Eli is survived by his wife, Dr. Cynthia David, an accomplished radiologist, his children Andrew and Emily, and his beloved dog "Hutch".

\section{REFERENCES}

1. Gale RP, Emil J. Freireich and Baruch Spinoza: birds of a feather? Leukemia. 2021;35:1812-3.

2. Gardner A, Mattiuzzi G, Faderl S, Borthakur G, Garcia-Manero G, Pierce S, et al. Randomized comparison of cooked and noncooked diets in patients undergoing remission induction therapy for acute myeloid leukemia. J Clin Oncol. 2008;26:5684-8.

3. Wathen JK, Thall PF, Cook JD, Estey EH. Accounting for patient heterogeneity in phase II clinical trials. Stat Med. 2008;27:2802-15.

4. Estey E, Othus M, Lee SJ, Appelbaum FR, Gale RP. New drug approvals in acute myeloid leukemia: what's the best end point? Leukemia. 2016;30:521-5.

5. Estey E, Gale RP. Acute myeloid leukemia therapy and the chosen people. Leukemia. 2017;31:269-71.

6. Estey E, Gale RP. How good are we at predicting the fate of someone with acute myeloid leukaemia? Leukemia. 2017;31:1255-8. 
7. Estey EH, Gale RP, Sekeres MA. New drugs in AML: uses and abuses. Leukemia. 2018;32:1479-81.

8. Estey E, Karp JE, Emadi A, Othus M, Gale RP. Recent drug approvals for newly diagnosed acute myeloid leukemia: gifts or a Trojan horse? Leukemia. 2020;34: 671-81.

9. Estey $E$, Pierce $S$. Routine bone marrow exam during first remission of acute myeloid leukemia. Blood. 1996;87:3899-902.

10. Estey E, Thall P, Beran M, Kantarjian H, Pierce S, Keating M. Effect of diagnosis (refractory anemia with excess blasts, refractory anemia with excess blasts in transformation, or acute myeloid leukemia [AML]) on outcome of AML-type chemotherapy. Blood. 1997;90:2969-77.

11. Estey EH, Hasserjian RP, Döhner H. Distinguishing AML from MDS: a fixed blast percentage may no longer be optimal. Blood. 2021. (in press).

12. Walter RB, Kantarjian HM, Huang X, Pierce SA, Sun Z, Gundacker HM, et al. Effect of complete remission and responses less than complete remission on survival in acute myeloid leukemia: a combined Eastern Cooperative Oncology Group, Southwest Oncology Group, and M. D. Anderson Cancer Center Study. J Clin Oncol. 2010;28:1766-71.

13. Walter RB, Appelbaum FR, Tallman MS, Weiss NS, Larson RA, Estey EH. Shortcomings in the clinical evaluation of new drugs: acute myeloid leukemia as paradigm. Blood. 2010;116:2420-8.

14. Estey E, Talpaz M, Kantarjian H. Remembering Emil J. Freireich: a portrait of courage and innovation in cancer research-March 16, 1927 to February 1, 2021. J Clin Oncol. 2021;39:2973-6.

\section{ACKNOWLEDGEMENTS}

RPG acknowledges support from the National Institute of Health Research (NIHR) Biomedical Research Centre funding scheme. Photograph reprinted with permission from the Seattle Cancer Care Alliance (Seattle, WA).

\section{COMPETING INTERESTS}

RPG is a consultant to BeiGene Ltd., Fusion Pharma LLC, LaJolla NanoMedical Inc. Mingsight Parmaceuticals Inc. CStone Pharmaceuticals, NexImmune Inc. and Prolacta Bioscience; advisor to Antengene Biotech LLC, Medical Director, FFF Enterprises Inc.; partner, AZAC Inc.; Board of Directors, Russian Foundation for Cancer Research Support; and Scientific Advisory Board: StemRad Ltd.

\section{ADDITIONAL INFORMATION}

Correspondence and requests for materials should be addressed to Roland B. Walter.

Reprints and permission information is available at http://www.nature.com/ reprints

Publisher's note Springer Nature remains neutral with regard to jurisdictional claims in published maps and institutional affiliations. 